\title{
anatomy
}

Editorial

www.anatomy.org.tr

doi:10.2399/ana.12.A/IV

\section{An Anatomy Congress of "Firsts": a debt of gratitude for Professor Alaittin Elhan}

\author{
Anatomy 2012; 6 Suppl: A/IV (C) 2012 TSACA
}

Dear Participants, Colleagues, Guests, and Dear Friends,

On behalf of the organizing committee, I have the great honor of welcoming you to the 4th International Symposium of Clinical and Applied Anatomy and 14th National Turkish Anatomy Congress in Ankara. This Congress will be an anatomy congress of "firsts" in Turkish Anatomy history.

In the history of our University, it will be the "first" time that an international and a national Anatomy meeting will take place at the same time. We have the honor and excitement to host more than 500 participants from 39 different countries which are Algeria, Antigua and Barbuda,Australia, Austria, Brazil, Bosnia and Herzegovina, Bulgaria, Cameroon, Czech Republic, Canada, Croatia, Congo-Kinshasa, Egypt, France, Georgia, Germany, Ghana, Greece, India, Iran, Iraq, Jordan, Korea, Malaysia, Nigeria, Portugal, Russia, Saudi Arabia, Serbia, Slovak Republic, Slovenia, South Africa, Sudan, Tunisia, Turkey, Ukraine, United Arab Emirates, United Kingdom, USA. We hope you to enjoy the outstanding scientific program that awaits you including more than 400 oral and poster presentations.

We are glad to have this rich scientific program and very proud to dedicate these meetings to our respected and veteran teacher, great anatomist, outstanding scientific person and an important milestone in the history of Anatomy in Turkey; Prof. Dr. Alaittin Elhan. During his 43 years of academic life he had left behind more than 30000 well trained medical and paramedical students, important textbooks, translated books, national and international publications, respectful colleagues and us; academic and technical staff of Ankara University, Department of Anatomy. And I am proud to announce that it will be the "first" time in Turkish Anatomy history that a Congress will be dedicated to a teacher.

This will be the "first" time that an Anatomy Congress will bring clinical disciplines together. Suiting well with the content of "Clinical and Applied Anatomy" we scheduled a satellite symposium in ISCAA including clinical sessions of 6 main surgical branches: Orthopedics and Traumatology, General Surgery, Plastic and Reconstructive Surgery, Ear, Nose and Throat Surgery, Neurosurgery and Anesthesiology and also Biomechanics. Our Department holds an honored position among these clinical dis- ciplines serving as a scientific lodge where all clinically oriented problems solved. Therefore, it is our wish that the scientific results of these symposiums will offer new perspectives and stimulates the creativity all Anatomists which will motivate us for future researches.

In the content of Orthopedics and Traumatology session there will be a webinar in which Prof. Dr. Alaittin Elhan will do a live dissection on knee joint. This dissection will be broadcasted online on a website simultaneously. And the attendants will watch this dissection in our congress hall at the same time. During this dissection there will be ongoing discussions between orthopedic surgeons at the dissecting room. This will also be the "first" time in Turkish Anatomy history that a webinar will take place. The video presentation of these discussions and the dissection will be distributed to all attendants of the congress and to all anatomists, orthopedic surgeons and physiotherapists in Turkey.

In these meetings we also didn't forget our students. As academic faculty members, in addition to give a good education, it is our responsibility to motivate our students for becoming future academic researchers. When they first step in Medical Faculty, we have to make them feel that they already become our colleagues and future collaborators. So again, for the "first" time in Turkish Anatomy history we will also host more than 150 students. We strongly suggest you to join their presentations and give them suggestions which will motivate them positively.

My "last" words will be to Prof. Dr. Alaittin Elhan:

My Dear Teacher, My Dear Colleague and My Dear Friend,

You are an excellent figure and a perfect example of how a teacher should be. You are an enthusiastic teacher, passionate and hardworking scientist, selfless and modest physician, man respecting the people, man of honesty and democracy. In the name of all your colleagues, I thank you and congratulate you to reach this academic career honorably and wish you best for the forthcoming years with your family. We all love you...

Sincerely

\section{Professor İbrahim Tekdemir, MD}

Congress President

Ankara, 2012 